\title{
Catalytic Specificity of Human Protein Tyrosine Kinases Revealed by Peptide Substrate Profiling
}

\author{
Julie Blouin, Philippe Roby, Mathieu Arcand, Lucille Beaudet and Francesco Lipari*
}

PerkinElmer Bio-discovery, 1744 William Street, Montreal, Quebec, H3J 1R4, Canada

\begin{abstract}
Out of the 90 human protein tyrosine kinases, 81 were assayed with short peptides derived from wellcharacterized [CDK1(Tyr15), IRS1(Tyr983), and JAK1(Tyr1023)] or generic [polyGlu:Tyr(4:1) and polyGlu:Ala:Tyr(1:1:1)] substrates. As expected, the CDK1 peptide is a substrate for all Src family kinases. On the other hand, some of the activities are novel and lead to a better understanding of the function of certain kinases. Specifically, the CDK1 peptide is a substrate for many of the Eph family members. Interestingly, profiling of nearly all the human protein tyrosine kinases revealed a distinct pattern of selectivity towards the CDK1 and IRS1 peptides.
\end{abstract}

Keywords: Peptide substrates, protein-tyrosine kinases.

\section{INTRODUCTION}

PTKs are involved in many cell signaling pathways. These enzymes represent early key regulators in such functions as cell growth, proliferation, differentiation, secretion, and apoptosis [1]. Aberrant protein kinase expression or function is a cause or consequence of many human diseases like cancer and atherosclerosis. As a result, kinases represent very important targets in the development of therapeutics.

Protein kinase selectivity is critical for appropriate intracellular signaling. Kinase-substrate interactions are mediated via specific interaction sites such as $\mathrm{SH} 2$ domains, but also by the distinct specificity of the catalytic domain. The use of small peptides to investigate kinase specificity and catalysis is supported by crystallographic structures of kinase-peptide complexes as well as studies with synthetic peptide libraries $[2,3]$. Considering that almost all human PTKs have recently become available as purified recombinant enzymes, it has become possible to profile peptide substrate activity throughout the entire group to possibly reveal novel specificities of individual kinases and kinase sub-families. Previously, a study was performed on the yeast kinome [4] in which nearly all (119) of the yeast protein kinases were overexpressed and assayed in a high-throughput manner on 17 chip-immobilized protein and peptide substrates. However, such an extensive investigation has not been performed with human PTKs.

In this study, three different peptides previously characterized with a small subset of $\operatorname{PTK}(s)$ were chosen for screening 81 human PTKs. The three peptides are derived from bona fide kinase substrate sequences and therefore represent putative in vivo targets. The CDK1 (Tyr15) or p34 ${ }^{\text {cdc2 }}$ (Tyr15) peptide was originally shown to be a suitable substrate for four Src kinases: SRC, LYN, LCK, and FYN [5].

*Address correspondence to this author at PerkinElmer Bio-discovery, 1744 William Street, Montreal, Quebec, H3J 1R4, Canada; Tel: 514-937-1010 ext: 314; Fax: 514-937-0777;

E-mail: francesco.lipari@perkinelmer.com
The IRS1 (Tyr983) peptide was chosen to represent a YMXM peptide. Peptides containing the YMXM motif were shown as effective substrates for receptor tyrosine kinases such as the insulin receptor [6], and also for non-receptor Tyr kinases [7]. Finally, the JAK1 (Tyr1023) peptide was shown to be a substrate for JAK3 [8]. In addition to the small peptides, the generic PTK substrates polyGT and polyGAT [9] were tested as controls of PTK activity.

The high-throughput TR-FRET platform, LANCE ${ }^{\circledR} U l$ tra, was used to measure enzyme activity, whereby the phosphopeptide product is detected by a highly sensitive anti-pTyr antibody labeled with europium chelate (Fig. 1). TR-FRET occurs between the chelate-labeled antibody and the dye-conjugated phosphopeptide upon excitation at 320 or $34 \mathrm{~nm}$.

Apart from providing valuable activity data for the 81 PTKs, the profiling experiments demonstrated that the CDK1 and IRS1 peptides are highly selective for certain kinase sub-families, whereas the polyGT, polyGAT, and JAK1 peptides are promiscuous. Furthermore, novel activities for certain kinases, such as the Eph family, have been observed.

\section{MATERIALS AND METHODS}

\section{Materials}

All peptides are available from PerkinElmer. The CDK1, IRS1, and JAK1 peptides are labeled with the small fluorescent dye ULight ${ }^{\mathrm{TM}}$ via conjugation to an $\mathrm{N}$-terminal Cys residue, whereas the polyGAT and polyGT are labeled via conjugation to the amino terminus of the polypeptides. ULight-polyGT (4:1) and ULight-polyGAT (1:1:1) are polymers of amino acids (20-50 kDa) in which the amino acid ratios are as indicated. ULight-CDK1 (Tyr15) has the sequence: CAGAGKIGEGTYGVVYK; ULight-IRS1 (Tyr983): CKKSRGDYMTMQIG; and ULight-JAK1 (Tyr1023): CAGAGAIETDKEYYTVKD. The biotinylated pTyr-peptide has the sequence: biotin-AGAGIGEGT (pY)GVVYK. Europium-anti-pTyr (PT66) Antibody was 
from PerkinElmer. All kinases were recombinant (human origin) and purchased from Carna Biosciences.

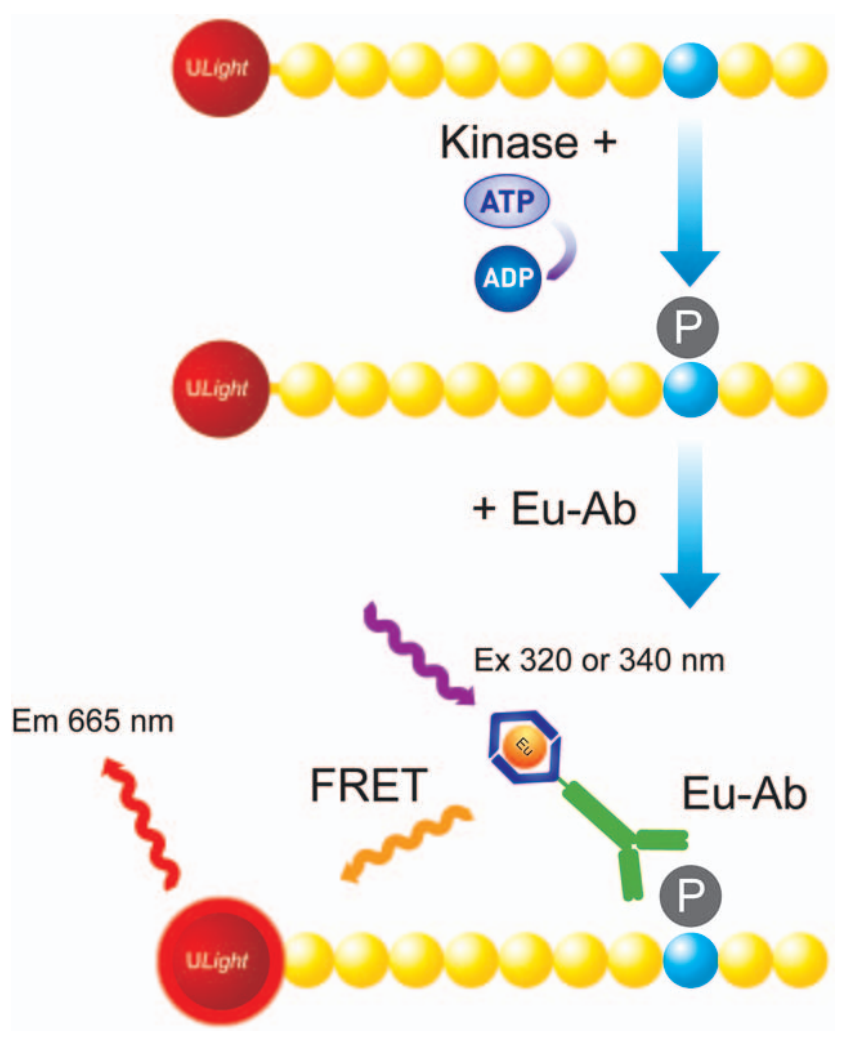

Fig. (1). LANCE Ultra TR-FRET technology for kinase assays. In these kinase assays, the binding of a Eu-labeled anti-phosphoTyr antibody (Eu-Ab) to the phosphorylated ULight-labeled substrate brings donor and acceptor molecules into close proximity. After irradiation of the kinase reaction at 320 or $340 \mathrm{~nm}$, the energy from the Eu donor is transferred to the ULight acceptor dye which, in turn, generates light at $665 \mathrm{~nm}$. The intensity of the light emission is proportional to the level of ULight-substrate phosphorylation.

\section{Methods}

The assays were performed in white, opaque OptiPlate $^{\mathrm{TM}}$-384 microplates from PerkinElmer. The kinase reaction buffer consisted of $50 \mathrm{mM}$ HEPES $\mathrm{pH} 7.5,1 \mathrm{mM}$ EGTA, $10 \mathrm{mM} \mathrm{MgCl} 2,2 \mathrm{mM}$ DTT and $0.01 \%$ Tween-20. EDTA, for stopping the reaction, and the detection antibody were prepared in LANCE Detection Buffer (PerkinElmer). All assay incubations were performed at $23^{\circ} \mathrm{C}$ and the microplates were sealed with TopSeal- $\mathrm{A}^{\mathrm{TM}}$ film (PerkinElmer) during that time. The fluorescence signals were read using an excitation filter of $320 \mathrm{~nm}$ and an emission filter of $665 \mathrm{~nm}$ on an EnVision ${ }^{\circledR}$ Multilabel Reader (PerkinElmer). The final assay volume was $20 \mu \mathrm{L}$.

For determination of kinase concentrations to use in the assays that would not interfere in detection by the antiphospho-Tyr (PT66) antibody, 0 to $30 \mathrm{nM}$ of each kinase was incubated with $50 \mathrm{nM}$ of biotinylated pTyr-peptide in the presence of $200 \mu \mathrm{M}$ ATP for $2 \mathrm{~h}$. The reaction was stopped by adding $10 \mathrm{mM}$ EDTA and $50 \mathrm{nM}$ ULightStreptavidin for 5 min. $2 \mathrm{nM}$ Europium-anti-pTyr (PT66) antibody was added and incubated for another $1 \mathrm{~h}$ before reading the fluorescence.

For kinase profiling, the kinase was incubated with 50 $\mathrm{nM}$ (ULight-CDK1 and ULight-JAK1) or $100 \mathrm{nM}$ (ULightIRS1, ULight-polyGT and ULight-polyGAT) substrate in the presence or absence of $200 \mu \mathrm{M}$ ATP. The enzyme reaction proceeded for $2 \mathrm{~h}$ before stopping with $10 \mathrm{mM}$ EDTA for 5 min. $2 \mathrm{nM}$ Europium-anti-pTyr antibody was added and incubated for another $1 \mathrm{~h}$ before reading the fluorescence. The $\mathrm{S} / \mathrm{B}$ ratio was calculated by dividing the fluorescence signal of the reaction with ATP by the signal from the reaction without ATP. All reactions were performed in duplicate and the average $\mathrm{S} / \mathrm{B}$ ratio is reported. Almost all of the individual duplicate values for the $\mathrm{S} / \mathrm{B}$ ratios were within $15 \%$ of the average values.

\section{RESULTS}

\section{Determination of the Concentration of Kinase to Use in the Assays}

The pTyr residues in the phosphopeptide products are detected by a highly specific anti-pTyr antibody. This antibody is highly promiscuous, since it is not specific for the peptide sequence surrounding the phosphorylated residue. In some cases, the kinase being analyzed contains Tyr autophosphorylation sites. Therefore, the pTyr residues on the kinase can compete for the binding of the antibody to the phosphopeptide product. Hence, the kinase concentration has to be low enough so that it does not interfere with the signal generation. To determine the concentration of kinase to use in the assay, tests with the kinase and a pre-phosphorylated peptide were performed. Sufficient ATP was added to allow for protein autophosphorylation. The fluorescence signal generated by the phosphorylated peptide was plotted versus the concentration of enzyme and an example plot for JAK2 kinase is illustrated in Fig. (2). In this case, $1 \mathrm{nM}$ of enzyme was chosen for substrate profiling since the signal begins to

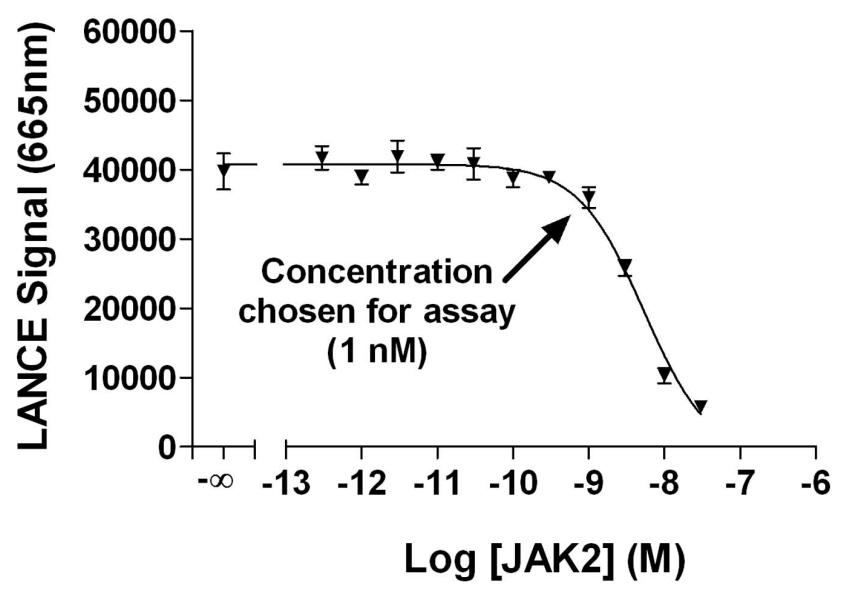

Fig. (2). Example competition curve.

The competition curve for JAK2 kinase was performed according to Materials and Methods. The fluorescence signal was plotted versus the concentration of enzyme and the highest concentration of enzyme providing minimal or no interference of signal was chosen for determination of activity versus the various ULight-substrates. In this case, $1 \mathrm{nM}$ kinase was chosen. The error bars represent the standard deviation of triplicate measurements. 
Table 1. Profiling Data for all Kinases.

A

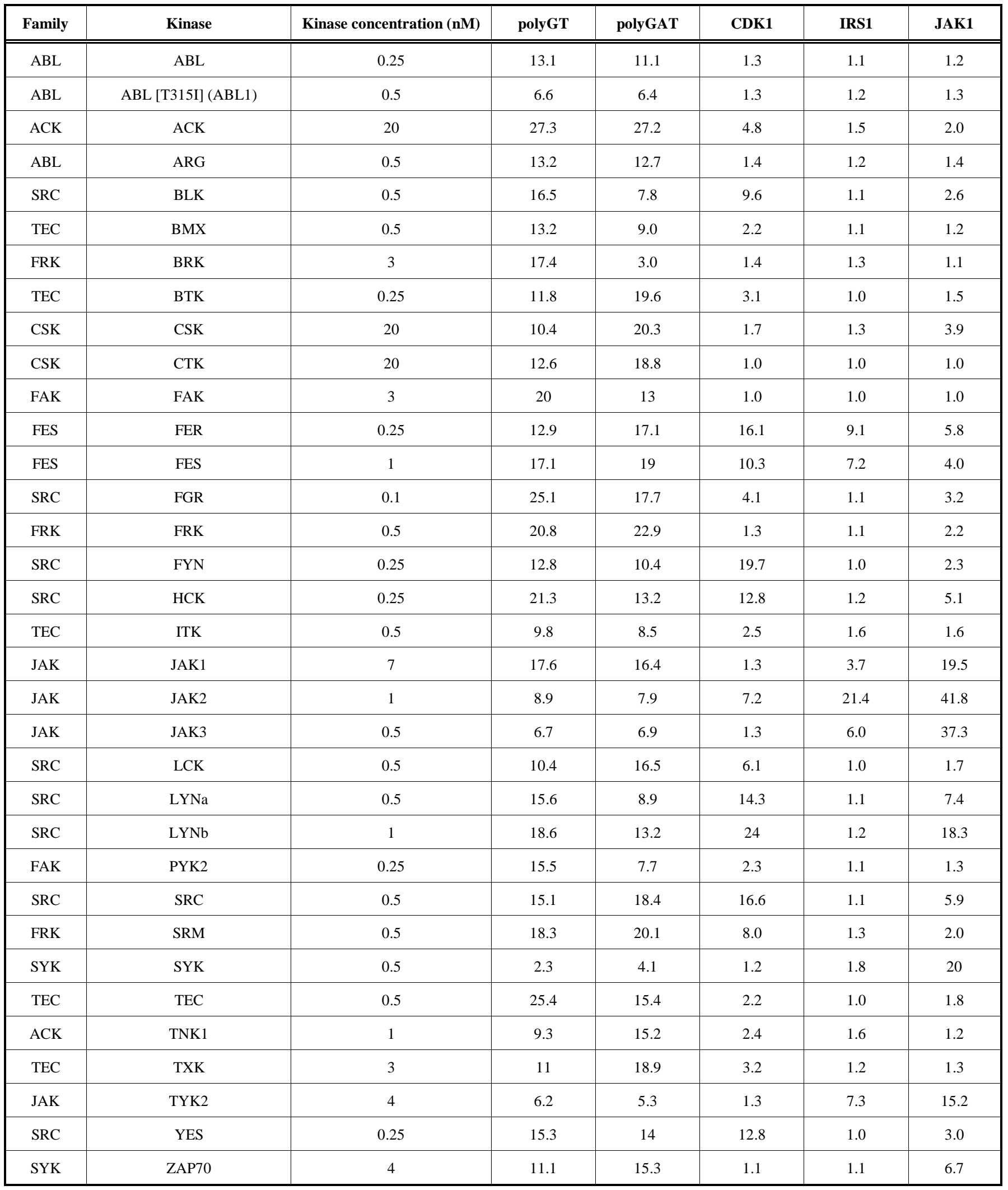


B

\begin{tabular}{|c|c|c|c|c|c|c|c|}
\hline Family & Kinase & Kinase concentration (nM) & polyGT & polyGAT & CDK1 & IRS1 & JAK1 \\
\hline ALK & ALK & 4 & 9.8 & 7.2 & 2.6 & 16.8 & 3.9 \\
\hline AXL & AXL & 4 & 9.8 & 5.6 & 1.5 & 1.6 & 1.2 \\
\hline DDR & DDR1 & 0.5 & 2.0 & 3.0 & 1.0 & 1.1 & 1.0 \\
\hline DDR & DDR2 & 0.5 & 4.1 & 5.1 & 1.0 & 4.9 & 1.0 \\
\hline EGFR & EGFR & 0.5 & 1.7 & 5.0 & 1.8 & 2.5 & 19 \\
\hline EGFR & EGFR [T790M] & 0.5 & 18.1 & 10.8 & 1.1 & 1.2 & 3.9 \\
\hline EPH & EphA1 & 0.5 & 24.1 & 11.4 & 3.1 & 1.2 & 1.2 \\
\hline EPH & EphA2 & 0.25 & 12.3 & 7.1 & 2.1 & 1.8 & 3.9 \\
\hline EPH & EphA3 & 0.5 & 17.4 & 8.0 & 4.4 & 3.5 & 3.8 \\
\hline EPH & EphA4 & 0.5 & 12.6 & 11.3 & 6.7 & 2.4 & 6.4 \\
\hline EPH & EphA5 & 1 & 18 & 21.9 & 19.2 & 7.6 & 21.2 \\
\hline EPH & EphA6 & 0.5 & 14.2 & 15.5 & 1.2 & 1.1 & 1.3 \\
\hline EPH & EphA7 & 0.5 & 22.7 & 11.1 & 1.4 & 1.3 & 1.5 \\
\hline EPH & EphA8 & 0.25 & 16.4 & 7.8 & 3.1 & 1.6 & 5.6 \\
\hline EPH & EphB1 & 0.5 & 25.1 & 7.9 & 14.1 & 8.4 & 10.6 \\
\hline EPH & EphB2 & 0.25 & 27.9 & 13.2 & 13.1 & 3.8 & 5.7 \\
\hline EPH & EphB3 & 0.1 & 29 & 11.2 & 8.3 & 2.3 & 4.0 \\
\hline EPH & EphB4 & 0.5 & 13.7 & 4.0 & 12.6 & 4.8 & 12 \\
\hline FGFR & FGFR1 & 0.5 & 2.9 & 5.0 & 1.6 & 13.5 & 30.8 \\
\hline FGFR & FGFR2 & 0.25 & 7.8 & 11.6 & 1.6 & 15.5 & 33.2 \\
\hline FGFR & FGFR3 & 0.25 & 16 & 10.7 & 1.4 & 8.1 & 27.6 \\
\hline FGFR & FGFR4 & 3 & 9.2 & 5.6 & 1.2 & 3.4 & 20.8 \\
\hline VEGFR & FLT1 & 0.25 & 22.2 & 15.4 & 1.1 & 1.9 & 10 \\
\hline PDGFR & FLT3 & 0.1 & 20.8 & 13.2 & 3.6 & 4.5 & 25 \\
\hline VEGFR & FLT4 & 0.25 & 6.9 & 6.5 & 1.8 & 11.4 & 36.9 \\
\hline PDGFR & FMS (CSFR) & 0.25 & 14.6 & 6.2 & 1.2 & 1.4 & 6.3 \\
\hline EGFR & HER2 & 10 & 9.3 & 8.4 & 1.1 & 1.1 & 1.4 \\
\hline EGFR & HER4 (ERBB4) & 0.1 & 25.2 & 14.4 & 1.1 & 1.1 & 1.5 \\
\hline INSR & IGF1R & 0.25 & 21.8 & 14.6 & 3.1 & 15.2 & 12.8 \\
\hline INSR & INSR & 20 & 18.3 & 25.4 & 1.1 & 3.2 & 1.6 \\
\hline INSR & IRR & 0.5 & 21.6 & 9.1 & 2.4 & 15.6 & 12.7 \\
\hline VEGFR & KDR & 0.25 & 8.6 & 4.3 & 1.3 & 5.1 & 30.8 \\
\hline PDGFR & KIT & 2 & 13 & 21.7 & 1.0 & 1.0 & 3.3 \\
\hline ALK & LTK & 1 & 21.3 & 25.1 & 2.4 & 3.9 & 2.7 \\
\hline AXL & MER & 0.25 & 29.2 & 15.9 & 9.7 & 5.6 & 3.2 \\
\hline MET & MET & 0.5 & 17 & 13.2 & 4.1 & 4.5 & 19.7 \\
\hline MUSK & MUSK & 1 & 2.5 & 10.6 & 1.8 & 1.1 & 3.9 \\
\hline PDGFR & PDGFRA & 0.5 & 17.8 & 10.6 & 1.3 & 2.4 & 9.0 \\
\hline
\end{tabular}




\begin{tabular}{|c|c|c|c|c|c|c|c|}
\hline PDGFR & PDGFRB & 0.25 & 11.2 & 12.5 & 1.6 & 2.0 & 3.0 \\
\hline MET & RON & 0.25 & 27.7 & 25.7 & 1.3 & 4.4 & 4.9 \\
\hline ROR & ROR1 & 20 & 3.4 & 1.5 & 0.9 & 1.0 & 1.0 \\
\hline ROS & ROS & 0.25 & 23.8 & 9 & 4.4 & 20.5 & 7.7 \\
\hline TIE & TIE2 & 0.5 & 19.3 & 9.4 & 1.6 & 2.1 & 5.4 \\
\hline TRK & TRKA (NTRK1) & 0.5 & 16.3 & 17.5 & 5.5 & 11.8 & 15.1 \\
\hline
\end{tabular}

The S/B ratios for each kinase are tabulated. The results are separated based on kinase type: A) Cytoplasmic or non-receptor Tyr kinases and B) Receptor Tyr kinases. The classification correlates with Robinson et al. [10] and Manning et al. [11].

decrease at $1 \mathrm{nM}$ of enzyme. For all the kinases, the highest concentration of enzyme providing no significant interference was chosen for determination of activity versus the various ULight-substrates. In a few cases, no interference was observed and $20 \mathrm{nM}$ enzyme was used for the reaction.

\section{Kinase Profiling}

81 human PTKs, plus two mutant kinases, Abl (T315I) and EGFR (T790M), were tested against the five substrates and the results are detailed in Table $\mathbf{1}$. The enzyme concentrations used varied from 0.1 to $20 \mathrm{nM}$, based on the potential interference of each enzyme in the phosphorylated peptide detection. The substrate concentrations used were $50 \mathrm{nM}$ or $100 \mathrm{nM}$ depending on the substrate. The substrate concentrations were optimized to obtain acceptable signals and S/B ratios, since it is known that the anti-pTyr antibody can have different affinities for various peptides. If substrate concentrations are too high, then non-specific fluorescence is generated due to random proximity of the europium-anti-pTyr antibody and ULight dye. The concentration of ATP was 200 $\mu \mathrm{M}$, and is non-limiting in the kinase reaction. All five substrates were assayed under very similar conditions for each enzyme. Therefore, the S/B value presented for each substrate is a representation of the relative activity of the enzyme for each substrate. For example, ABL gave S/B values of 13 and 11 for polyGT and polyGAT, respectively. However, the other three substrates provided no signal at equivalent enzyme concentration.

PolyGT gave an S/B ratio > 3 for 77 kinases. Interestingly, SYK, DDR1, EGFR, FGFR1, MUSK, and RET did not show $\mathrm{S} / \mathrm{B}$ ratios greater than 3 , but some minimal activity between an S/B ratio of 1.4 and 2.9 was observed.

PolyGAT gave an S/B ratio > 3 for 81 kinases. Only ROR1 and ROR2 did not work with polyGAT, although S/B ratios of 3.4 and 4.2 were observed with polyGT for these two enzymes.

The CDK1 peptide was a very good substrate for two PTK families: Eph and Src. Only the EphA2, A6 and A7 enzymes showed minimal activity out of the $12 \mathrm{EPH}$ enzymes tested. All of the Src family kinases tested had significant activity with the CDK1 peptide.

For the IRS1 peptide, 32 kinases, from 14 families, had an S/B ratio > 3. Only two of these families (6 kinases) were of the cytoplasmic or non-receptor type: Jak and Fes.

For the JAK1 peptide, 50 kinases, from 19 families, had an $\mathrm{S} / \mathrm{B}$ ratio $>3$. Some kinases were quite selective for the JAK1 peptide compared to the other four substrates, including EGFR, FLT4, JAK3, KDR, RET, and SYK, where the $\mathrm{S} / \mathrm{B}$ ratio was at least 3-fold higher than with the other four substrates.

\section{DISCUSSION}

In the present work, almost all of the human PTKs were assayed with five peptidic substrates using a TR-FRET technology and purified recombinant enzymes. A unique pattern of human PTK selectivity was observed for the CDK1 and IRS1 peptides, whereas polyGT and polyGAT were substrates for almost all of the kinases and JAK1 was active with over $60 \%$ of the kinases. In order to visually demonstrate the selectivity of the peptide substrates, the activity of the PTKs towards the JAK1, CDK1, and IRS1 peptides is illustrated in dendrogram format in Fig. (3). In contrast to the JAK1 peptide, where almost all branches are highlighted with active kinases, the CDK1 and IRS1 peptides are only substrates for certain sub-families.

It was clearly observed that, indeed, polyGT and polyGAT can be considered as universal substrates for Tyr kinases and serve as good positive controls for PTK activity. On the other hand, using these non-specific substrates may be a disadvantage, because contaminating Tyr kinases may generate a signal that is not due to the kinase being studied. Polymeric peptides containing acidic amino acids and Tyr were originally described about 25 years ago [9]. To our knowledge, this is the first time that these polymeric peptides have been tested with such a wide variety of Tyr kinases. 
JAK1 peptide phosphorylation

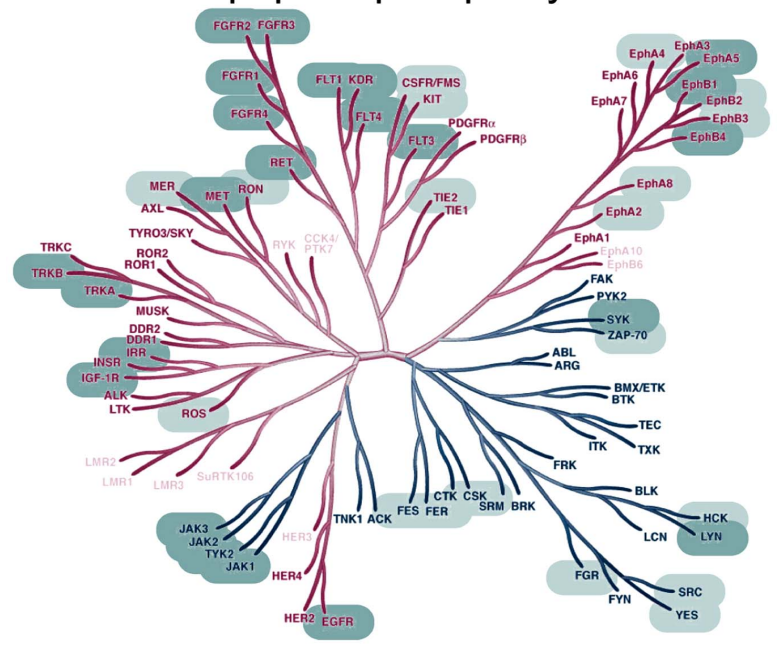

CDK1 peptide phosphorylation

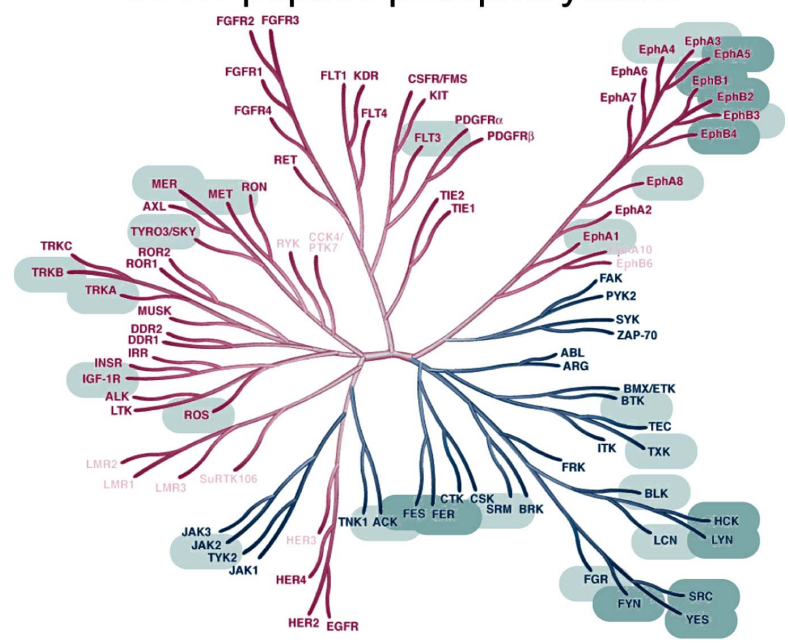

IRS1 peptide phosphorylation

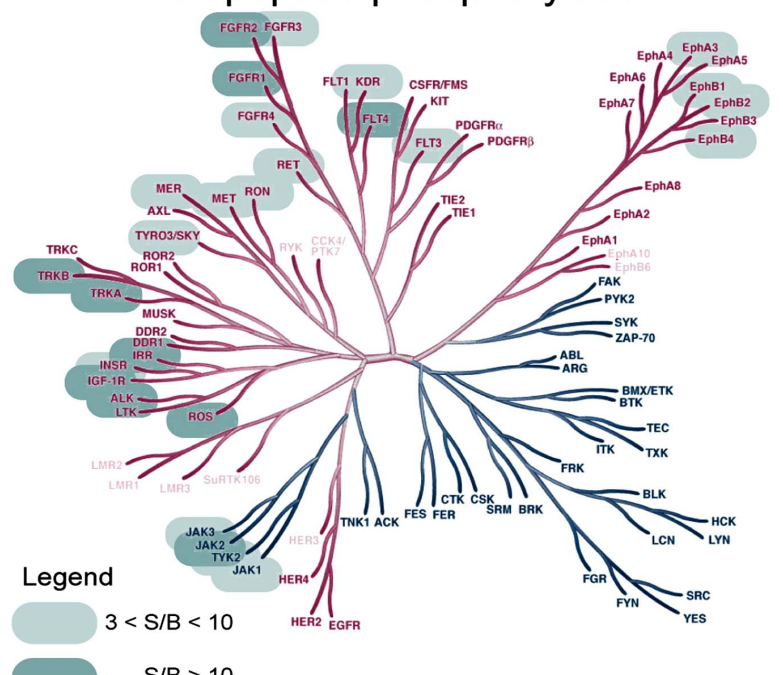

$\mathrm{S} / \mathrm{B}>10$

Fig. (3). Dendrograms of PTK peptidic substrate selectivity.

Kinases with S/B ratios greater than 3 are highlighted. The names of the kinases not tested were faded out. Dendrogram illustration reproduced courtesy of Cell Signaling Technology, Inc. (www.cellsignal.com).
Interestingly, the JAK1 peptide seemed to be promiscuous for many Tyr kinases and it also represented a better substrate than polyGT and polyGAT in some cases. This broad activity may be related to the fact that it contains three acidic residues proximal to the Tyr residues: ETDKEYY. As for the polyGT and polyGAT polymers, the presence of acidic amino acids may cause the JAK1 peptide to be a nonspecific substrate for Tyr kinases. The lack of specificity towards the JAK1 peptide may also be a caution in other studies of peptide substrate specificity of PTKs. PTK binding to acidic peptides may be unrelated to the specificity of the kinase, but to a general structural preference of all the PTKs.

In the current study, all Src family kinases efficiently utilized the CDK1 peptide as a substrate and further demonstrates the overall preference of the Src family for the CDK1 peptide [5]. Interestingly, two of the three members of the Src-related Frk family, BRK and FRK, do not phosphorylate the CDK1 peptide, although both phosphorylated polyGT and polyGAT. Although the Frk family of kinases has sequence homology to the Src family, the catalytic specificities of the two families are different, further demonstrating the distinct nature of the Frk family of kinases [12].

The ability of almost all Eph kinases to phosphorylate the CDK1 peptide was not predicted. A single report implicating EphA5 as a putative kinase phosphorylating CDK5 Tyr15 has been published [13], and the preference of the Eph family towards this substrate was not revealed by previous studies using synthetic peptides against the EphA3 and EphA4 kinases $[14,15]$. However, the sequence around Tyr15 in CDK5, KIGEGTYGTVFK, is very similar to the CDK1 peptide in this study: KIGEGTYGVVYK. This is the first time that the Eph family has been shown to directly phosphorylate the CDK-1 (Tyr-15) sequence. The Eph family of receptors is of particular importance due to their role in communication between adjacent cells and there are strong efforts to understand the complex signaling mechanisms of these PTKs [16].

In the current study, 26 of the 32 kinases found to be active against the IRS1 peptide were receptor Tyr kinases, demonstrating that the IRS1 peptide is greatly favored by receptor Tyr kinases. Also, the IRS1 peptide was a very good substrate for JAK-1, 2, and 3 kinases, which are cytoplasmic kinases. The activity of the JAK kinases towards IRS1 has been previously reported [17]. Moreover, Jak family kinases show more sequence homology to receptor Tyr kinases than to cytoplasmic Tyr kinases. Indeed, the kinases acting on the IRS1 peptide tend to group entirely on the left side of the dendrogram shown in Fig. (3).

Overall, a high-throughput assay technology was used to profile five Tyr kinase substrates. The CDK1 and IRS1 peptides demonstrated high selectivity for certain subfamilies, whereas the JAK1 peptide is promiscuous. Furthermore, this is the first publication showing the specificity of the Eph family towards the CDK1 (Tyr-15) sequence. Researchers may refer to this study to identify possible substrates for their kinase(s) of interest or to set-up kinase assays to further study the structure and function of the PTK(s).

\section{ACKNOWLEDGEMENTS}

The authors thank Martina Bielefeld-Sevigny for encouraging this research study. 


\section{CONFLICTS OF INTEREST}

None Declared.

\section{ABBREVIATIONS}

$$
\begin{array}{ll}
\text { polyGT } & \text { polyGlu:Tyr }(4: 1) \\
\text { polyGAT } & =\text { polyGlu:Ala:Tyr }(1: 1: 1) \\
\text { pTyr } & =\text { phosphorylated tyrosine } \\
\text { PTK } & =\text { protein tyrosine kinase } \\
\mathrm{S} / \mathrm{B} & =\text { signal to background } \\
\text { TR-FRET } & =\text { time-resolved fluorescence resonance energy } \\
& \text { transfer }
\end{array}
$$

\section{REFERENCES}

[1] Gschwind A, Fischer OM, Ullrich A. The discovery of receptor tyrosine kinases: targets for cancer therapy. Nat Rev Cancer 2004; 4(5): 361-70.

[2] Hubbard SR. Crystal structure of the activated insulin receptor tyrosine kinase in complex with peptide substrate and ATP analog. EMBO J 1997; 16(18): 5572-81.

[3] Songyang Z, Carraway KL, Eck MJ, et al. Catalytic specificity of protein-tyrosine kinases is critical for selective signalling. Nature 1995; 373(6514): 536-9.

[4] Zhu H, Klemic JF, Chang S, et al. Analysis of yeast protein kinases using protein chips. Nat Genet 2000; 26(3): 283-9.

[5] Cheng HC, Nishio H, Hatase O, Ralph S, Wang JH. A synthetic peptide derived from $\mathrm{p} 34^{\mathrm{cdc} 2}$ is a specific and efficient substrate of src-family tyrosine kinases. J Biol Chem 1992; 267(13): 9248-56.

[6] Shoelson SE, Chatterjee S, Chaudhuri M, White MF. YMXM motifs of IRS-1 define substrate specificity of the insulin receptor kinase. Proc Natl Acad Sci USA 1992; 89(6): 2027-31.
[7] Garcia P, Shoelson SE, George ST, Hinds DA, Goldberg AR, Miller WT. Phosphorylation of synthetic peptides containing TyrMet-X-Met motifs by nonreceptor tyrosine kinases in vitro. J Biol Chem 1993; 268(33): 25146-51.

[8] Wang R, Griffin PR, Small EC, Thompson JE. Mechanism of Janus kinase 3-catalyzed phosphorylation of a Janus kinase 1 activation loop peptide. Arch Biochem Biophys 2003; 410(1): 7-15.

[9] Braun S, Raymond WE, Racker E. Synthetic tyrosine polymers as substrates and inhibitors of tyrosine-specific protein kinases. J Biol Chem 1984; 259(4): 2051-4

[10] Robinson DR, Wu YM, Lin SF. The protein tyrosine kinase family of the human genome. Oncogene 2000; 19(49): 5548-57.

[11] Manning G, Whyte DB, Martinez R, Hunter T, Sudarsanam S. The protein kinase complement of the human genome. Science 2002 298(5600): 1912-34

[12] Serfas MS, Tyner AL. Brk, Srm, Frk, and Src42A form a distinct family of intracellular Src-like tyrosine kinases. Oncol Res 2003; 13(6-10): 409-19.

[13] Cheng Q, Sasaki Y, Shoji M, et al. Cdk5/p35 and Rho-kinase mediate ephrin-A5-induced signaling in retinal ganglion cells. Mol Cell Neurosci 2003; 24(3): 632-45.

[14] Warner N, Wybenga-Groot LE, Pawson T. Analysis of EphA4 receptor tyrosine kinase substrate specificity using peptide-based arrays. FEBS J 2008; 275(10): 2561-73.

[15] Davis TL, Walker JR, Allali-Hassani A, Parker SA, Turk BE, DhePaganon S. Structural recognition of an optimized substrate for the ephrin family of receptor tyrosine kinases. FEBS J 2009; 276(16): 4395-404.

[16] Pasquale EB. Eph-ephrin bidirectional signaling in physiology and disease. Cell 2008; 133(1): 38-52.

[17] Yin T, Keller SR, Quelle FW, et al. Interleukin-9 induces tyrosine phosphorylation of insulin receptor substrate-1 via JAK tyrosine kinases. J Biol Chem 1995; 270(35): 20497-502.

(C) Blouin et al.; Licensee Bentham Open.

This is an open access article licensed under the terms of the Creative Commons Attribution Non-Commercial License (http://creativecommons.org/licenses/by-nc/3.0/) which permits unrestricted, non-commercial use, distribution and reproduction in any medium, provided the work is properly cited. 